\title{
Homocysteine and cobalamin status in German vegans
}

\author{
Annika Waldmann ${ }^{1}$, Jochen W Koschizke ${ }^{1}$, Claus Leitzmann ${ }^{2}$ and Andreas Hahn ${ }^{1, *}$ \\ 'Institute of Food Science, University of Hanover, Wunstorfer Strasse 14, D-30453 Hanover, Germany: \\ ${ }^{2}$ Institute of Nutrition Science, Justus-Liebig-University Giessen, Germany
}

Submitted 9 June 2003: Accepted 3 September 2003

\begin{abstract}
Objective: The study aimed to evaluate the homocysteine and cobalamin status of German vegans and determine whether the intake of very small amounts of foods of animal origin can improve this status.

Design and setting: Cross-sectional study, Germany.

Subjects: The dietary and nutritional intakes of 131 vegans ( 73 women, 58 men; age range: $20.2-82.1$ years) were evaluated using a general questionnaire and two foodfrequency questionnaires.

Results: The prevalence of inadequate cobalamin status in volunteers of the German Vegan Study was 28.2\%, and that of hyperhomocysteinaemia, 38.1\%. Moderate vegans were affected to a lesser extent than were strict vegans. Duration of veganism and cobalamin concentration were inversely correlated (Spearman's $r=-0.175$, $P=0.047)$. Folate concentration and erythrocyte aspartic acid aminotransferase activity were not correlated with plasma homocysteine concentration, but duration of veganism correlated positively with homocysteine concentration (Spearman's $r=0.319, P<0.001)$. Cobalamin and homocysteine concentrations were inversely correlated (when controlling for duration of veganism; $r=-0.602, P<0.001$ ).

Conclusion: Cobalamin status needs to be improved in order to minimise the risk of hyperhomocysteinaemia.
\end{abstract}

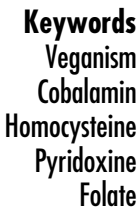

Hyperhomocysteinaemia is considered to be an independent risk factor for vascular diseases of the coronary, cerebral and peripheral arteries. An increase in total plasma homocysteine of only $5 \mathrm{moll}^{-1}$ is estimated to result in a $50-80 \%$ increased risk for cerebrovascular or coronary artery disease ${ }^{1}$. To date, no standardised definition of hyperhomocysteinaemia exists ${ }^{2,3}$. Elevated plasma homocysteine concentration results from either genetic defects and/or nutritional deficiencies of the vitamins involved in the metabolism of homocysteine: pyridoxine, cobalamin and folic acid. Selhub et $a l^{3}$ estimated that at least two-thirds of cases of hyperhomocysteinaemia are due to inadequate cobalamin, pyridoxine or folate status.

In general, omnivores obtain a sufficient supply of cobalamin - with the exception of sufferers of chronic atrophic gastritis - since meat and animal products are reliable sources for the vitamin. However, omnivores may have low folate intakes due to lower vegetable intake. Hyperhomocysteinaemia in healthy omnivores is therefore more likely to be related to low folate intake rather than to cobalamin deficiency ${ }^{4}$. In vegetarians and especially in vegans, a different situation can be assumed. Owing to the absence of cobalamin in plant foods (unless contaminated with faecal matter or fortified), vegans are more likely to be at risk of cobalamin deficiency but show high folate intakes and blood folate concentrations ${ }^{5-9}$, whereas lacto-ovo vegetarians consume reasonable amounts of cobalamin in the form of eggs and/or dairy products $^{10-12}$. The strongest inverse association between cobalamin and homocysteine concentration is found in vegetarians, whereas in omnivores the (inverse) association between folic acid and homocysteine is the stronger one $e^{7,13-15}$.

In order to investigate the cobalamin and homocysteine status of German vegans and to evaluate whether the consumption of small amounts of eggs and dairy products can improve cobalamin status (and decrease homocysteine concentrations), strict and moderate vegans were included in the German Vegan Study (GVS).

\section{Methods}

Subjects for the GVS (designed as a cross-sectional study) were recruited by means of advertisements. Dietary intakes and nutritional intakes were evaluated by means of a general questionnaire and two 9-day food-frequency questionnaires. The GVS cohort was subdivided into strict and moderate vegans according to dietary intake: strict vegans (SV) consuming a pure vegan diet and moderate 
vegans (MV) consuming a maximum of $5 \%$ of total energy from eggs and/or dairy products. The following data illustrate that the dietary intake of moderate vegans was much more similar to that of the strict vegans than to the dietary intake of lacto-ovo vegetarians, and that it made more sense to name them moderate vegans rather than restricted lacto-ovo vegetarians. They consumed only very small amounts of products of animal origin: the mean daily intake was $4.05 \mathrm{~g}$ of milk, $1.64 \mathrm{~g}$ of butter, $1.48 \mathrm{~g}$ of cheese and $0.95 \mathrm{~g}$ of eggs $^{16}$.

Altogether, 131 persons (who took no cobalamin supplements) participated in all study segments and fulfilled the following study criteria: 'strict' vegan diet $(n=86)$ or 'moderate' vegan diet $(n=45)$ for at least 1 year prior to the start of the study, minimum age of 18 years and no pregnancy or childbirth during the previous 12 months.

An automated chemiluminescence system (ACS:180; Ciba Corning, Fernwald, Germany) was used to measure plasma cobalamin and red blood cell (RBC) folate concentrations $^{17-19}$. Plasma homocysteine concentrations were measured by high-performance liquid chromatography (Immunodiagnostic AG, Bensheim, Germany) ${ }^{20}$. Pyridoxine status was analysed by measuring the erythrocyte aspartic acid aminotransferase (EAST) activity after stimulation (EPOS Analyzer 5060; Eppendorf, Hamburg, Germany) ${ }^{21}$. The haemoglobin-cyanide method was used to measure haemoglobin ${ }^{22-24}$, and RBC mean cell volume (MCV) was determined with a Coulter $^{\circledR}$ STKS (Beckman Coulter; VCS Technology, Krefeld, Germany).

\section{Ethical considerations}

The GVS was conducted in accordance with the Helsinki Declaration of 1964 as revised in 1983 and 1996. Since there was no intervention, the Ethics Commission of Lower Saxony confirmed that ethical approval was not required. All subjects participated voluntarily and gave written consent prior to starting the study.

\section{Statistical analysis}

A statistical analysis program (SPSS 10.0.7; SPSS, Inc., Chicago, IL, USA) was used to analyse the data. Results are shown as mean \pm standard deviation or median (5th/95th percentile). Normal distribution of the data was checked using the Kolmogorov-Smirnov test. In the case of skewness, the Mann-Whitney $U$-test was used to reveal significant differences between the two groups; given a normal distribution the independent-samples $t$-test was used. For nominal data the chi-square test was used to evaluate statistically significant differences. Partial correlation was used to detect associations between (log) cobalamin and (log) homocysteine plasma concentrations while controlling for the duration of vegan diet. The relative risks of suffering from marginal pyridoxine supply and of being cobalamin-deficient were computed by means of incidence rates. As the results were not influenced by age, the calculations were not adjusted for age. Statistical significance was set at the 0.05 level; significance levels quoted are two-sided.

\section{Results}

\section{Characteristics of the study participants}

The characteristics of the GVS participants with respect to dietary subgroup allocation are shown in Table 1.

\section{Homocysteine, cobalamin, folate and pyridoxine}

Table 2 shows that homocysteine concentrations were significantly higher and cobalamin concentrations were significantly lower in strict vegans than in moderate vegans. The median plasma concentration of homocysteine in the GVS cohort was $12.7 \mu \mathrm{moll}^{-1}$. However, homocysteine concentrations were significantly higher $(P<0.001$, Mann-Whitney $U$-test) in men (median: $15.9 \mu \mathrm{moll}^{-1}$ ) than in women (median: $10.6 \mu \mathrm{moll}^{-1}$ ). The prevalence of homocysteine concentration $\geq 15 \mathrm{mmoll}^{-1}$ was $38.1 \%$ (SV: $45.3 \%$, MV: $24.4 \%$, men: 55.2\%, women: $24.7 \%$ ). About two-thirds of the cohort showed homocysteine concentrations $\geq 10 \mu \mathrm{moll}^{-1}$ (SV: 70.9\%, MV: 62.2\%, men: 82.8\%, women: 56.2\%). Homocysteine concentration increased with the duration of following a vegan diet (Spearman's $r=0.319$, $P<0.001)$. No association was found between homocysteine and age. After controlling for the duration of veganism, the correlation between (log) cobalamin and (log) homocysteine was strong, inverse and statistically

Table 1 Characteristics of participants in the German Vegan Study (values are expressed as mean \pm standard deviation)

\begin{tabular}{lcrr}
\hline & Strict vegans $(n=86)$ & Moderate vegans $(n=45)$ & $P$-value \\
\hline Males/females (\%) & $48.8 / 51.2$ & $35.6 / 64.4$ & $0.146^{*}$ \\
Age (years) & $43.8 \pm 15.6$ & $44.6 \pm 15.0$ & $0.762 \dagger$ \\
Body mass index $\left(\mathrm{kg} \mathrm{m}^{-2}\right)$ & $21.5 \pm 2.66$ & $21.3 \pm 2.11$ & $0.699 \dagger$ \\
Duration of vegan diet (years) & $7.14 \pm 6.69$ & $4.69 \pm 2.97$ & $0.072 \ddagger$ \\
Energy intake (MJ day ${ }^{-1}$ ) & $8.60 \pm 3.05$ & $7.35 \pm 2.16$ & $\mathbf{0 . 0 1 6 \dagger}$ \\
Energy derived from products of animal origin (\%) & 0.00 & $1.17 \pm 1.07$ & $<\mathbf{0 . 0 0 1 \dagger}$ \\
\hline
\end{tabular}

* Chi-square test.

†Independent-samples $t$-test.

‡Mann-Whitney U-test. 
Table 2 Status of homocysteine and related vitamins of participants in the German Vegan Study (values are expressed as median (5th/95th percentile))

\begin{tabular}{lccr}
\hline & $\begin{array}{c}\text { Strict vegans } \\
(n=86)\end{array}$ & $\begin{array}{c}\text { Moderate vegans } \\
(n=45)\end{array}$ & $P$-value \\
\hline $\begin{array}{c}\text { Homocysteine } \\
\left(\mu \text { moll }^{-1}\right)\end{array}$ & $13.4(6.03 / 82.5)$ & $12.3(4.61 / 23.6)$ & $\mathbf{0 . 0 2 2}^{*}$ \\
Males & $11.2(5.14 / 60.9)$ & $10.3(4.35 / 23.5)$ & $0.200^{*}$ \\
$\quad$ Females & $17.3(6.15 / 85.8)$ & $14.3(5.50 / 36.0)$ & $0.124^{*}$ \\
$\begin{array}{c}\text { Cobalamin } \\
(\text { pmoll }\end{array}$ & $122(71.2 / 276)$ & $185(97.6 / 689)$ & $<\mathbf{0 . 0 0 1}^{*}$ \\
Males & $138(88.0 / 373)$ & $199(107 / 765)$ & \\
$\quad$ Females & $113(65.2 / 274)$ & $151(87.1 / 490)$ & $\mathbf{0 . 0 1 1 \dagger}$ \\
$\begin{array}{c}\text { Folate } \\
\left.\text { (nmoll }{ }^{-1}\right)\end{array}$ & $33.6(19.4 / 46.3)$ & $35.1(18.9 / 45.3)$ & $0.925 \dagger$ \\
Males & $35.9(20.9 / 45.5)$ & $36.3(19.4 / 45.8)$ & $0.865 \dagger$ \\
$\quad$ Females & $32.8(17.9 / 46.6)$ & $30.4(11.6 / 45.3)$ & $0.631 \dagger$ \\
EAST activity & $1.60(1.30 / 2.00)$ & $1.60(1.15 / 1.98)$ & $0.730^{*}$ \\
$\quad$ Males & $1.60(1.31 / 2.05)$ & $1.60(1.10 / 1.95)$ & $0.097 \dagger$ \\
Females & $1.50(1.30 / 2.00)$ & $1.60(1.40 / 2.00)$ & $0.260^{*}$ \\
\hline
\end{tabular}

EAST - erythrocyte aspartic acid aminotransferase.

* Mann-Whitney U-test.

†Independent-samples $t$-test.

significant $(r=-0.602, P<0.001)$. In the German Vegan Study, homocysteine concentrations were not associated with folate and pyridoxine values (data not shown). The median plasma cobalamin concentration of the GVS cohort was $147 \mathrm{pmoll}^{-1}$. Men showed statistically significant lower median plasma cobalamin concentrations than did women $(P=0.003$, Mann-Whitney $U$-test $)$, at 123 and $165 \mathrm{pmoll}^{-1}$, respectively; and moderate vegans showed higher median plasma cobalamin concentrations than strict vegans (Table 2). Only $14.5 \%$ of the GVS cohort had plasma cobalamin concentrations $>258 \mathrm{pmoll}^{-1}$ (SV: $8.14 \%$, MV: $26.7 \%$ ), whereas the prevalence of values $<110$ pmoll $^{-1}$ was $28.2 \%$ (SV: $39.5 \%$, MV: $6.67 \%$ ). The relative risk of being cobalamin-deficient $\left(<110 \mathrm{pmoll}^{-1}\right)$ was 5.93 for strict vegans compared with moderate vegans. Using the higher cut-off point of $\leq 156 \mathrm{pmol}^{-1}$ for cobalamin deficiency, more than half of the cohort would be classified as deficient (SV: 65.5\%, MV: 37.8\%). The duration of following a vegan diet was inversely associated with plasma cobalamin concentration (Spearman's $r=-0.175, P=0.047)$. The relative risk of being cobalamin-deficient was 1.81 for long-term vegans ( $\geq 5$ years) compared with short-term vegans $(<5$ years). Additional signs of cobalamin deficiency are decreased haemoglobin concentration $\left(<120 \mathrm{gl}^{-1}\right.$ for females, $<140 \mathrm{gl}^{-1}$ for males) and elevated MCV ( $\left.>96 \mathrm{fl}\right)$. Concentrations of homocysteine and haemoglobin and MCV levels of the cobalamin-deficient subgroup $\left(<110 \mathrm{pmoll}^{-1}\right)$ are shown in Table 3 . It is obvious that more strict vegans than moderate vegans suffered from cobalamin deficiency. Nearly three-quarters of the subgroup show stage III cobalamin deficiency and about half show stage IV cobalamin deficiency.

In the GVS cohort folate concentrations were comparatively high in both groups, with slightly higher median
Table 3 Homocysteine, mean cell volume (MCV) and haemoglobin in the cobalamin-deficient subgroup of participants in the German Vegan Study (values are expressed as median (5th/95th percentile))

\begin{tabular}{ccc}
\hline & $\begin{array}{c}\text { Strict vegans } \\
(n=34)\end{array}$ & $\begin{array}{c}\text { Moderate } \\
\text { vegans }(n=3)\end{array}$ \\
\hline Homocysteine $\left(\mu \mathrm{mol} \mathrm{I}^{-1}\right)$ & $22.7(8.40 / 110)$ & $16.6(15.9 / 23.9)$ \\
$>15 \mu \mathrm{moll}^{-1}$ & $n=24$ & $n=3$ \\
$>10 \mu \mathrm{moll}^{-1}$ & $n=31$ & $n=3$ \\
$\mathrm{MCV}(\mathrm{fl})$ & $96.5(80.8 / 110)$ & $87.0(85.0 / 91.0)$ \\
$>96 \mathrm{fl}$ & $n=17$ & $n=0$ \\
Haemoglobin $\left(\mathrm{gl}^{-1}\right)$ & $140(120 / 163)$ & $135(134 / 140)$ \\
Females $<120 \mathrm{gl}^{-1}$, & $n=5$ & $n=1$ \\
Males $<140 \mathrm{gl}^{-1}$ & & \\
\hline
\end{tabular}

concentrations in moderate vegans than in strict vegans. The prevalence of high EAST activity values $(>1.85$; indicating a low pyridoxine status) was $21.8 \%$ in strict vegans and $13.2 \%$ in moderate vegans. The relative risk of marginal pyridoxine supply was 1.65 for strict vegans compared with moderate vegans.

\section{Discussion}

In this study, the plasma homocysteine, cobalamin, folate and pyridoxine concentrations of German vegans were investigated. The GVS cohort was subdivided according to dietary intake into strict vegans (SV) and moderate vegans (MV). These subgroups did not differ in anthropometric data or the duration of following a vegan diet ${ }^{16}$. Previous data $^{2,5}$ have suggested that a vegetarian/vegan diet is related to elevated plasma homocysteine concentrations that lower the benefits of these diets regarding cardiovascular disease (CVD). From epidemiological studies it is known that there is an association between hyperhomocysteinaemia and the occurrence of myocardial infarcts. Despite the fact that there are no data to show that an elevated homocysteine concentration is a causative factor in the development of atherosclerosis, some authors consider hyperhomocysteinaemia to be an important and independent risk factor for $\mathrm{CVD}^{1,25}$. The 'normal' range for total plasma homocysteine $e^{25,26}$ is approximately 5-15 $\mu \mathrm{moll}^{-1}$, while plasma homocysteine concentration in the range of $15-30 \mu \mathrm{moll}^{-1}$ is considered to indicate moderate hyperhomocysteinaemia ${ }^{25,27}$. Stein and McBride $^{26}$ have suggested that the upper limit of $15 \mathrm{mmoll}^{-1}$ for normal plasma homocysteine values should be revised to lower values, since the risk of atherosclerosis is already increased within this range. Cutoff points of $12 \mu \mathrm{moll}^{-1}$ (reference 27) and $10 \mu \mathrm{moll}^{-1}$ (reference 28) have been discussed as upper levels for plasma homocysteine.

In the cohort investigated, the prevalence of plasma homocysteine concentration $>15 \mu \mathrm{moll}^{-1}$ was $36 \%$. The incidence of hyperhomocysteinaemia was higher for strict vegans than for moderate vegans and higher for men than 
for women. The prevalence of homocysteine concentration $>10 \mu \mathrm{moll}^{-1}$ was $67 \%$. Again, more strict vegans than moderate vegans and more men than women showed homocysteine concentrations above this cut-off point. Krajcovicova-Kudlackova et al. ${ }^{5}$ reported a prevalence of hyperhomocysteinaemia $\left(>15 \mu \mathrm{moll}^{-1}\right)$ of $53 \%$ among vegans and $29 \%$ among vegetarians. Their mean homocysteine concentrations of 15.8 and $13.2 \mu \mathrm{moll}^{-1}$, respectively, were higher than in the GVS cohort. Herrmann et al. $^{2}$ documented similar median homocysteine concentrations: $15.2 \mu \mathrm{moll}^{-1}$ for vegans and $11.0 \mu \mathrm{moll}^{-1}$ for lacto-ovo vegetarians, and the prevalence of homocysteine concentration $>15 \mu \mathrm{moll}^{-1}$ was $57 \%$ and $12 \%$, respectively. Homocysteine concentrations of $<8 \mu \mathrm{moll}^{-1}$ are desirable for the prevention of $\mathrm{CVD}^{29}$ and were prevalent in $23 \%$ of the GVS cohort. More moderate vegans than strict vegans and more women than men were in this desirable range of $<8 \mu \mathrm{moll}^{-1}$ (Table 2). In accordance with the findings from other studies ${ }^{3,30}$, men in our study showed statistically significant higher plasma homocysteine concentrations than did women (difference: $5 \mu \mathrm{moll}^{-1}, P<0.001$, Mann-Whitney $U$-test). This may partly be due to a difference in vitamin status, since significant differences were found for cobalamin plasma concentrations (difference: $50 \mathrm{pmoll}^{-1}, P=0.005$, Mann-Whitney $U$-test), but also reflects the influence of $17 \beta$-oestradiol ${ }^{25,31}$. Correlations between the dietary intakes of cobalamin, folate and pyridoxine and corresponding plasma concentrations were not found.

In contrast to the hyperhomocysteinaemia in omnivores, the higher homocysteine concentrations in vegetarians and vegans are probably not a consequence of folate deficiency but of cobalamin deficiency ${ }^{5}$. At the time of blood sampling we considered plasma cobalamin concentrations $<110 \mathrm{pmol}^{-1}$ to be indicative of cobalamin deficiency. Cobalamin deficiency can be divided into four stages. In stages I and II, plasma and cell stores become depleted. Stage III is indicated by increased concentrations of homocysteine and methylmalonic acid. Stage IV is characterised by elevated MCV and/or lowered haemoglobin ${ }^{7}$. Since a low (total) cobalamin concentration marks only the final stage of cobalamin deficiency, this parameter is a late indicator of negative cobalamin status. Therefore, higher concentrations should be used as cut off-points ${ }^{11}$. Currently a number of different reference levels have been suggested. Herrmann et $a l^{2}$ used a concentration of $156 \mathrm{pmoll}^{-1}$ as lower reference level. Concentrations $<220 \mathrm{pmoll}^{-1}$ were considered to be abnormal by Hokin and Butler ${ }^{32}$ and Herbert ${ }^{11}$, whereas Spoelhof ${ }^{33}$ discussed a cobalamin concentration of $258 \mathrm{pmoll}^{-1}$ as cut-off point.

Cobalamin deficiency was found in $26 \%$ of the GVS participants with a cut-off point of $110 \mathrm{pmoll}^{-1}$; nearly three-quarters of these persons showed stage III cobalamin deficiency and about half could be considered as stage IV cobalamin-deficient. Serum cobalamin concentration was $<156 \mathrm{pmoll}^{-1}$ in $52 \%$ of the investigated GVS participants. This value is in agreement with Donaldson ${ }^{34}$. He summarised findings from 12 studies concerning cobalamin status in vegetarian/vegan diets, and found overall that $50 \%$ of the studies' participants could be considered as cobalamin-deficient. Armstrong et al. ${ }^{35}$ and Dong and $\mathrm{Scott}^{36}$ were able to show that cobalamin concentrations decrease with increasing avoidance of animal-derived products. In the GVS cohort, the moderate vegans consumed only very small amounts of products of animal origin, but even these small amounts of animalderived food were able to improve their cobalamin status. The median cobalamin concentrations of GVS participants were rather low compared with other studies. Herrmann et $a .^{2}{ }^{2}$ reported median cobalamin concentrations of $217 \mathrm{pmoll}^{-1}$ without characterising the duration of the vegan diet. Krajcovicova-Kudlackova et al. ${ }^{5}$ documented mean concentrations of $140.1 \mathrm{pmoll}^{-1}$ for vegan and $214.8 \mathrm{pmol}^{-1}$ for vegetarian subgroups. In their study, the period of veganism/vegetarianism was quite long: 7.87 and 8.85 years, respectively. Haddad et al. ${ }^{8}$ reported an even higher mean concentration of $312 \mathrm{pmoll}^{-1}$ for vegans. The mean duration of veganism in their cohort was 4.2 years. In agreement with Dong and $\mathrm{Scott}^{36}$ and Miller et al. ${ }^{37}$, our results for the GVS cohort show a weak but significant negative correlation between cobalamin concentration and the duration of veganism (Spearman's $r=-0.203$, $P=0.013)$. The correlation analyses indicated a significant inverse association for (log) cobalamin and (log) homocysteine $(r=-0.602, P<0.001)$ after controlling for duration of vegan diet. These findings are in agreement with other results that indicate an inverse association for cobalamin and homocysteine $e^{2,3,5,14}$. Although studies with omnivores show a strong inverse relationship for plasma folate and homocysteine $\mathrm{e}^{3,14}$ and, to a lesser extent, associations between pyridoxine and homocysteine ${ }^{3}$, no correlations between homocysteine and either pyridoxine or folate, respectively, were found for the GVS participants. These results bear analogy to those of Quinlivan et $a l^{38}$, who concluded that cobalamin is the main determinant of homocysteine in cohorts with high folate intakes.

In conclusion, our findings show that even a small amount of food of animal origin can improve cobalamin and homocysteine status. In order to minimise the risk of cobalamin deficiency and hyperhomocysteinaemia, regular supplementation of cobalamin in the nationally recommended amount should be considered by strict and moderate vegans.

\section{Acknowledgements}

This study was supported by the Stoll VITA Foundation, Waldshut-Tiengen, Germany and the EDEN Foundation, Bad Soden, Germany.

A.W. analysed the data and wrote the paper with the co-authors. J.W.K. and A.H. co-ordinated the study, and 
organised blood sampling and data collection. A.H. and C.L. originated and designed the study.

\section{References}

1 Boushey CJ, Beresford SA, Omenn GS, Motulsky AG. A quantitative assessment of plasma homocysteine as a risk factor for vascular disease. Probable benefits of increasing folic acid intakes. Journal of the American Medical Association 1995; 274: 1049-57.

2 Herrmann W, Schorr H, Purschwitz K, Rassoul F, Richter V. Total homocysteine, vitamin $\mathrm{B}_{12}$ and total antioxidant status in vegetarians. Clinical Chemistry 2001; 47: 1094-101.

3 Selhub J, Jacques PF, Wilson PWF, Rush D, Rosenberg IH. Vitamin status and intake as primary determinants of homocysteinemia in an elderly population. Journal of the American Medical Association 1993; 270: 2693-98.

4 Pietrzik K, Broenstrup A. Vitamins $\mathrm{B}_{12}, \mathrm{~B}_{6}$ and folate as determinants of homocysteine concentration in the healthy population. European Journal of Pediatrics 1998; 157(Suppl. 2): 135S-8S.

5 Krajcovicova-Kudlackova M, Blazicek P, Kopcova J, Bederova A, Babinska K. Homocysteine levels in vegetarians versus omnivores. Annals of Nutrition \& Metabolism 2000; 44: $135-8$.

6 Koebnick C, Heins UA, Hoffmann I, Dagnelie PC, Leitzmann C. Folate status during pregnancy in women is improved by long-term high vegetable intake compared with the average Western diet. Journal of Nutrition 2000; 131: 733-9.

7 Herbert V Vitamin B-12. In: Ziegler EE, Hiler LJ Jr, eds. Present Knowledge in Nutrition. Washington, DC: ILSI Press, 1996; 191-205.

8 Haddad EH, Berk LS, Kettering JD, Hubbard RW, Peters WR. Dietary intake and biochemical, hematologic, and immune status of vegans compared with nonvegetarians. American Journal of Clinical Nutrition 1999; 80(Suppl. 3): 586S-93S.

9 Abdulla M, Andersson I, Asp NG, Berthelsen K, Birkhed D, Dencker I, et al. Nutrient intake and health status of vegans. Chemical analyses of diets using the duplicate portion sampling technique. American Journal of Clinical Nutrition 1981; 24: 2464-77.

10 Rauma AL, Törrönen R, Hänninen O, Mykkänen H. Vitamin B-12 status of long-term adherents of a strict uncooked vegan diet ('living food diet') is compromised. Journal of Nutrition 1995; 125: 2511-5.

11 Herbert V. Staging vitamin B-12 (cobalamin) status in vegetarians. American Journal of Clinical Nutrition 1994; 59(Suppl. 5): 1213S-22S.

12 Alexander D, Ball MJ, Mann J. Nutrient intake and haematological status of vegetarians and age-sex matched omnivores. European Journal of Clinical Nutrition 1994; 48 : $538-46$

13 Eikelboom JW, Lonn E, Genest J Jr, Hankey G, Yusuf S. Homocyst(e)ine and cardiovascular disease: a critical review of the epidemiologic evidence. Annals of Internal Medicine 1999; 131: 363-75.

14 Verhoef P, Stampfer MJ, Buring JE, Gaziano JM, Allen RH, Stabler SP, et al. Homocysteine metabolism and risk of myocardial infarction: relation with vitamins $\mathrm{B}_{6}, \mathrm{~B}_{12}$ and folate. American Journal of Epidemiology 1996; 143: $845-59$.

15 Guttormsen AB, Schneede J, Ueland PM, Refsum H. Kinetics of total plasma homocysteine in subjects with hyperhomocysteinemia due to folate or cobalamin deficiency. American Journal of Clinical Nutrition 1996; 63: $194-202$.
16 Waldmann A, Koschizke JW, Leitzmann C, Hahn A. Dietary intakes and lifestyle factors of a vegan population in Germany: results from the German Vegan Study. European Journal of Clinical Nutrition 2003; 57: 947-55.

17 Chen IW, Sperling MI, Heminger LA. Vitamin $\mathrm{B}_{12}$. In: Pesce AJ, Kaplan LA, eds. Clinical Chemistry: Theory, Analysis, and Correlation. St Louis, MO: CV Mosby, 1989; 569-73.

18 Brewster MA. Vitamins. In: Pesce AJ, Kaplan LA, eds. Clinical Chemistry: Theory, Analysis, and Correlation. St Louis, MO: CV Mosby, 1989; 543-68.

19 McNeely MD. Folic acid. In: Pesce AJ, Kaplan LA, eds. Clinical Chemistry: Theory, Analysis, and Correlation. St Louis, MO: CV Mosby, 1989; 539-42.

20 Ubbink JB, Hayward Vermaak WJ, Bissbort S. Rapid highperformance liquid chromatographic assay for total homocysteine levels in human serum. Journal of Chromatography 1991; 565: 441-6.

21 Canham JE, Sauberlich HE, Baker EM, Raica J, Herman YE. Biochemical assessment of the biochemical status of vitamin $\mathrm{B}_{6}$ in the human. American Journal of Clinical Nutrition 1972; 25: 629-42.

22 International Committee for Standardization in Haematology of the European Society of Haematology. Recommendations and requirements for haemoglobin in human blood. Journal of Clinical Pathology 1965; 18: 353.

23 Zijlstra WG, van Kampen EJ. Standardization of hemoglobinometry. III. Preparation and use of a stable hemiglobin-cyanide standard. Clinica Chimica Acta 1962; 7: 96-9.

24 Zijlstra WG, van Kampen EJ. Standardization of hemoglobinometry. I. The extinction coefficient of hemiglobincyanide. Clinica Chimica Acta 1960; 5: 719-29.

25 Refsum H, Ueland PM, Nygard O, Vollset SE. Homocysteine and cardiovascular disease. Annual Review of Medicine 1998; 49: 31-62.

26 Stein JH, McBride EP. Hyperhomocysteinemia and atherosclerotic vascular disease. Archives of Internal Medicine 1998; 158: 1301-6.

27 Welch GN, Loscalzo J. Homocysteine and atherothrombosis. New England Journal of Medicine 1998; 338: $1042-50$.

28 Gerhard GT, Duell PB. Homocysteine and atherosclerosis. Current Opinion in Lipidology 1999; 10: 417-28.

29 Woodside JV, Yarnell JW, McMaster D, Young IS, Harmon DL, McCrum EE, et al. Effect of B-group vitamins and antioxidant vitamins on hyperhomocysteinemia: a double-blind, randomized, factorial-design, controlled trial. American Journal of Clinical Nutrition 1996; 67: 858-66.

30 DeRose DJ, Charles-Marcel ZL, Jamison JM, Muscat JE, Braman MA, McLane GD, et al. Vegan diet-based lifestyle program rapidly lowers homocysteine levels. Preventive Medicine 2000; 30: 225-33.

31 Wouters MG, Moorrees MT, van der Mooren MJ, Blom HJ, Boers GH, Schellekens LA, et al. Plasma homocysteine and menopausal status. European Journal of Clinical Investigation 1995; 25: 801-5.

32 Hokin BD, Butler T. Cyanocobalamin (vitamin B-12) status in Seventh-day Adventist ministers in Australia. American Journal of Clinical Nutrition 1999; 70(Suppl. 3): 576S-8S.

33 Spoelhof GD. Reliability of serum $\mathrm{B}_{12}$-levels in the diagnosis of $\mathrm{B}_{12}$-deficiency [Letter to the Editor]. American Family Physician 1996; 54: 465-8.

34 Donaldson MS. Metabolic vitamin B-12 status on a mostly raw vegan diet with follow-up using tablets, nutritional yeast, or probiotic supplements. Annals of Nutrition $\mathcal{G}$ Metabolism 2000; 44: 229-34.

35 Armstrong BK, Davis RE, Nivol DJ, van Merwyk AJ, Larwood CJ. Hematological, vitamin B12 and folate studies 
on Seventh-day Adventist vegetarians. American Journal of Clinical Nutrition 1974; 27: 712-8.

36 Dong A, Scott SC. Serum vitamin B12 and blood-cell values in vegetarians. Annals of Nutrition \& Metabolism 1982; 4 209-16.

37 Miller DR, Specker BL, Ho MI, Norman EJ. Vitamin B12 status in a macrobiotic community. American Journal of Clinical Nutrition 1991; 53: 524-9.

38 Quinlivan EP, McPartlin J, McNulty H, Ward M, Strain JJ, Weir DG, et al. Importance of both folic acid and vitamin B12 in reduction of risk of vascular disease. Lancet 2002; 359: $227-8$. 